\title{
CONCEPTS
}

\section{The UIAA Medical Commission Injury Classification for Mountaineering and Climbing Sports}

\author{
Volker Schöffl, Priv-Doz, Dr med, MHBA; Audry Morrison, BSc; Urs Hefti, Dr med; Schwarz Ullrich, Dr med; \\ Thomas Küpper, Priv-Doz, Dr med \\ From the Department of Sportorthopedics—Sporttraumatologie, Department for Orthopedic and Trauma Surgery, Klinikum Bamberg, Germany (Dr \\ Schöffl); Department for Trauma Surgery, Friedrich Alexander University Erlangen-Nuremberg, Germany (Dr Schöff); Medical Commission UIAA, \\ Bern, Switzerland (Drs Schöff, Hefti, and Küpper); Medical Commission UIAA, London, UK (Mrs Morrison); Private Clinic, Oberstdorf, Germany \\ (Dr Schwarz); Institute of Occupational \& Social Medicine, Aachen Technical University, Germany (Dr Küpper).
}

Objective.-Variations in definitions, scores, and methodologies have created differences in the results and conclusions obtained from studies on mountaineering and climbing sports injuries and illnesses; this has made interstudy comparisons difficult or impossible. To develop a common, simple, and sport-specific scoring system to classify injuries and illnesses in mountaineering and climbing studies; such retrospective scoring would facilitate the analysis and surveillance of their frequencies, severity and fatalities, and outcomes of any treatment.

Methods.-The UIAA (The International Mountaineering and Climbing Federation) makes recommendations, sets policy, and advocates on behalf of the climbing and mountaineering community internationally through its various commissions. Using a nominal group consensus model approach, a working group was formed during the UIAA Medical Commission's meeting in Adršpach - Zdoňov, in the Czech Republic, 2008. This group critically examined climbing and other relevant literature for various methodological approaches in measuring injury incident rates and severity, including data sources, and produced a working document that was later edited and ratified by all members of the UIAA Medical Commission.

Results.-Definitions of injury location, injury classification, and fatality risk are proposed. Case fatality, time-related injury risk, and a standardized metric climbing difficulty scale are also defined.

Conclusions.-The medical commission of the UIAA recommends the use of the described criteria and scores for future research in mountaineering and climbing sports in order to enable robust and comprehensive interstudy comparisons and epidemiological analysis.

Key words: mountaineering, rock climbing, ice climbing, climbing injuries, climbing epidemiology

The version presented here was approved by written consent in lieu of a live meeting on May 10, 2010 (www.theuiaa.org/medical_advice.html).

Members of UIAA MedCom (in alphabetical order): C. Angelini (Italy), B. Basnyat (Nepal), J. Bogg (Sweden), A.R. Chiocconi (Argentina), N. Dikic (Serbia), W. Domej (Austria), P. Dobbelaar (Netherlands), E. Donegani (Italy), S. Ferrandis (Spain), U. Gieseler (Germany), U. Hefti (Switzerland), D. Hillebrandt (UK), J. Holmgren (Sweden), M. Horii (Japan), D. Jean (France), A. Koukoutsi (Greece), A. Kokrin (Russia), J. Kubalova (Czech Republic), T. Küpper (Germany), J. McCall (Canada), H. Meijer (Netherlands), J. Milledge (UK), A. Morrison (UK), H. Mosaedian (Iran), R. Naeije (Belgium), M. Nakashima (Japan), S. Omori (Japan), P. Peters (Luxembourg), I. Rotman (Czech Republic), V. Schöffl (Germany), J. Shahbazi (Iran), J.C. Skaiaa (Norway), J. Venables (New Zealand), J. Windsor (UK).

Corresponding author: Volker Schöffl, Priv-Doz, Dr med, MHBA, Department of Sportorthopedics-Sporttraumatologie, Department for Orthopedic and Trauma Surgery, Klinikum Bamberg, Germany, Department for Trauma Surgery, Friedrich Alexander University Erlangen-Nuremberg, Germany, Medical Commission UIAA, Bern, Switzerland, and Klinikum Bamberg, Bugerstrasse 80, 96049 Bamberg, Germany (e-mail: volker.schoeffl@me.com).

\section{Introduction}

In the past 20 years, several studies (pro- and retrospectively) were conducted to evaluate the injury and fatality risk of rock, ${ }^{1-18}$ ice, ${ }^{19,20}$ and mountain climbing. ${ }^{16-18,21-30}$ The reporting methods varied in each of the studies. For example, injury incidence was reported per 1000 hours of sport-specific performance in some studies but reported in expedition days or summit attempts in others. Objective reporting of the body injury site and its severity also varied in most of these papers according to the injury definition and methodology used. This has created differences in the injury and fatality results and conclusions, which in turn has made interstudy comparisons difficult or impossible.

In the absence of a sport-specific injury and illness incidence and severity scoring system, some authors have used the NACA (National Advisory Committee for Aeronautics) score, while others have used the AIS (Ab- 
breviated Injury Scale) or ISS score (Injury Severity Score). ${ }^{17-19}$ The NACA score is a prehospital score and does not show patient outcome. A NACA score from 3 to 6 can either have a good or a fatal outcome and is therefore not appropriate. The AIS describes the severity of injury to 1 body region: 1 Minor, 2 Moderate, 3 Serious, 4 Severe, 5 Critical, 6 Maximal (currently untreatable). It is mostly used for polytrauma classification and not very specific on minor grade injuries, which are more common in mountaineering and climbing sport injury evaluations. The ISS is based upon the AIS and has certain idiosyncrasies that both impair its predictive power and complicate its calculation. All of these scores demonstrate weaknesses in the evaluation of mountaineering and climbing injuries, ${ }^{18,19}$ as they do not present treatment outcome, give sport-specific references such as climbing grades, or assess the climbing risk.

The difficulties in reporting the variables involved in climbing and mountaineering injuries and illnesses were recently reviewed. ${ }^{18}$ These sports differ when compared to each other (eg, ice climbing vs bouldering), and collectively when compared to many mainstream sports such as football, skiing, cycling, and others. Mainstream sports often involve international standardized rules and are played with consistent circumstances (eg, soccer pitch, $100 \mathrm{~m}$ race, $90 \mathrm{~min}$ game, fixed team numbers) enforced by referees or judges. Climbing sports do not have such rigid rules or organization.

Any standardized sport-specific injury or illness (trauma or medical) data collection form should be easy to use by all types of medical coverage personnel. The classifications and codes used should translate well to epidemiological analysis. Although researchers may choose to add variables to their study, some standardized common baseline measurements should exist.

There is a recent trend in sports medicine towards sport-specific injury reporting to increase interstudy comparability. For example, in football (soccer) the FIFA Medical Assessment and Research Centre established an International Injury Consensus Group which prepared a consensus statement on injury definitions and data collection procedures in studies on football injuries. ${ }^{31}$ Following a successful pilot study, ${ }^{18}$ a similar procedure was proposed for mountaineering and climbing sports under the auspices of the Medical Commission of the UIAA (International Mountaineering and Climbing Federation, UIAA MedCom, www.theuiaa.org). The UIAA represents 90 member federations from 62 different countries on all continents. The medical commission of the UIAA developed a set of criteria and scores for future research in mountaineering and climbing sports in order to enable robust and comprehensive interstudy comparisons and epidemiological analysis.

\section{Methods}

Using a nominal group consensus model approach, ${ }^{32}$ a working group was formed during the UIAA Medical Commission's meeting in Adršpach - Zdoňov, in the Czech Republic, 2008. After critically analyzing the current literature, ${ }^{1-30,33}$ a working document was prepared and circulated via e-mail. Following several revisions, this final version was approved by written consent in lieu of a live meeting by UIAA MedCom on May 10, 2010.

\section{Recommendations}

\section{INJURY AND ILLNESS}

The nature of the medical problem should be described. An injury (trauma) is defined as: any physical complaint due to an external or internal force sustained by a participant during trekking, mountaineering, or climbing activity. Injuries include acute external trauma resulting from falls, rock fall, and blunt or pointed trauma, as well as trauma due to internal forces such as tendon tears, muscular injury, and fatigue fractures. Frostbite (coldinduced tissue injury) is classified as an injury as it is a reaction to an external condition-exposure to extreme cold. The activities include belaying, ascent to and descent from the climb, and camp time during expeditions.

An illness (medical condition) is defined as: any affliction to a participant during trekking, mountaineering, or climbing, including ascent and descent to the climb and camp time for expeditions. High-altitude diseases are classed as illnesses. As the classification and diagnosis of high altitude illnesses may vary internationally, when using this protocol to collect data the following should be classed as "illnesses:" acute mountain sickness (AMS), high-altitude pulmonary edema (HAPE), and high-altitude cerebral edema (HACE). Hypothermia should be listed as an "illness" as it affects virtually every organ system in the body. Other illnesses include fever, infection, diarrhea, tonsillitis, and heart failure.

Other scores and classifications use the terms trauma and medical instead of injury and illness. Nevertheless, we think these nomenclatures are interchangeable.

\section{SCORING SYSTEMS}

A scoring system-the Injury and Illness Severity Classification (IIC) UIAA MedCom Score-was adapted from the NACA score ${ }^{34}$ and should be used for classification in mountain and climbing sports. A retrospective scoring of the injury is recommended as this would reflect the patient's treatment outcome and mortality. The proposed protocol to record injuries in mountaineer- 
Table 1. Main groupings and categories for classifying injury location: Anatomical sites according to OSICS $10^{31,35,37}$

\begin{tabular}{|c|c|c|}
\hline Main grouping & Category & $\begin{array}{c}\text { Equivalent OSICS } \\
\text { (Orchard Sports Injury } \\
\text { Classification System) } \\
\text { body area character }\end{array}$ \\
\hline \multirow[t]{2}{*}{ Head and neck } & Head/face & $\mathrm{H}$ \\
\hline & Neck/cervical spine & $\mathrm{N}$ \\
\hline \multirow[t]{6}{*}{ Upper limbs } & Shoulder/clavicle & $\mathrm{S}$ \\
\hline & Upper arm & $\mathrm{U}$ \\
\hline & Elbow & $\mathrm{E}$ \\
\hline & Forearm & $\mathrm{R}$ \\
\hline & Wrist & $\mathrm{W}$ \\
\hline & Hand/finger/thumb & $\mathrm{P}$ \\
\hline \multirow[t]{5}{*}{ Trunk } & Chest (sternum/ribs) & $\mathrm{C}$ \\
\hline & Thoracic spine & $\mathrm{D}$ \\
\hline & Trunk, abdomen & $\mathrm{O}$ \\
\hline & Lumbar spine & $\mathrm{B}$ \\
\hline & Pelvis and buttock & $\mathrm{L}$ \\
\hline \multirow[t]{6}{*}{ Lower limbs } & Hip/groin & $\mathrm{G}$ \\
\hline & Thigh & $\mathrm{T}$ \\
\hline & Knee & $\mathrm{K}$ \\
\hline & Lower leg & Q \\
\hline & Ankle & A \\
\hline & Foot/toe & $\mathrm{F}$ \\
\hline $\begin{array}{l}\text { Location } \\
\text { unspecified }\end{array}$ & & $X$ \\
\hline
\end{tabular}

ing and climbing studies is broken down into 3 simple components:

Injury location-main body parts are designated by a letter of the alphabet following the Orchard Sports Injury Classification System (OSICS) (Table 1).

Injury and Illness Severity Classification-this is numerically rated from 0 to 6 .

Fatality risk-numerically rated from I to IV and/or the case fatality can be calculated.

\section{INJURY LOCATION}

To report an injury location, we recommend to use the current OSICS, version $10^{34}$ for its reliability, ${ }^{35}$ simplicity, and ease of access. It has been available as a free download on the Internet since 2002 (http://www.injuryupdate.co$\mathrm{m} . \mathrm{au} / \mathrm{research} / \mathrm{OSICS} . \mathrm{htm}$ ), and was originally developed in 1992 for Australian football and rugby. ${ }^{36}$

\section{SEVERITY CLASSIFICATION}

Injury and Illness Severity Classification (IIC) - UIAA MedCom Score

0 No injury or illness
1 Mild injury or illness, no medical intervention necessary, self therapy (eg bruises, contusions, strains)

2 Moderate severe injury or illness, not life threatening, prolonged conservative or minor surgery, outpatient therapy, doctor attendance within a short time frame (days), injury-related work absence, heals without permanent damage (eg, undisplaced fractures, tendon ruptures, pulley ruptures, dislocations, meniscal tear, minor frostbite)

3 Major injury or illness, not life-threatening, hospitalization, surgical intervention necessary, immediate doctor attendance necessary, injury-related work absence, heals with or without permanent damage (eg, dislocated joint, fractures, vertebral fractures, cerebral injuries, frostbite with amputations)

4 Acute mortal danger, polytrauma, immediate prehospital doctor or experienced trauma paramedic attendance if possible, acute surgical intervention, outcome: alive with permanent damage

5 Acute mortal danger, polytrauma, immediate prehospital doctor or experienced trauma paramedic attendance if possible, acute surgical intervention, outcome: death

6 Immediate death

In contradiction to the NACA score ${ }^{34}$ the UIAA MedCom Score is retrospective, considers outcome and mortality, and gives exact guidelines for classification.

\section{FATALITY RISK CLASSIFICATION}

This grading system is similar to the British "E" grades in rock climbing that rate both the physical difficulty of the route as well as the overall risk.

Fatality Risk Classification (FRC)

I Fatalities are technically possible, but very rare. No objective danger. For example, indoor climbing

II Few objective dangers, fatalities rare, falls are not very dangerous, risk is mostly calculable, for example, sport climbing, low elevation, and technically easy peaks

III High objective danger, risk is difficult to calculate, falls lead frequently to injuries, fatalities more frequent. For example, traditional climbing, high Himalayan (7000-8000 m), or difficult peaks

IV Extremely dangerous, falls have a high fatality rate, totally unjustified to normal mortals

\section{CASE FATALITY}

An alternative option and/or addition to the FRC is to calculate the case fatality rate. The case fatality or mor- 
tality rate is defined by the ratio of deaths within a designated population of people with a particular condition (eg, number of summit attempts), during a stated timeframe. However, it may be difficult to quantify the population and timeframe precisely in climbing studies. Ideally, the case fatality and fatality risk classification should both be presented.

\section{TIME-RELATED INJURY RISK}

In order to compare the risk of injury in climbing sports to other sports, future studies should calculate an injury risk per 1000 hours of sport specific performance (timerelated injury risk, morbidity rate) as this measure is increasingly used in scientific analysis. If the hours are not collected for individual rock climbing days, each day can be calculated as 4 hours for sport and traditional climbing, 8 hours for alpine climbing, 2 hours for indoor climbing, 6 hours for ice climbing, and 16 hours for an expedition day. The 16-hour expedition day estimate is based on 12 hours of climbing time, 4 hours of camp activity, and 8 hours of sleep, and reflects the very small risk of an injury being sustained during camp time and sleep (eg, avalanche). All of these hours (especially for the expedition day) are estimations and have been agreed upon by the UIAA Medical Commission to enable calculations of injury risk per 1000 hours of sport specific performance. However, expedition studies should continue to calculate injury risk per day as the preferred and widely accepted calculation method. ${ }^{33,38}$ The above given estimation should only be added if a comparison per 1000 hours is necessary.

\section{CLIMBING AND MOUNTAINEERING GRADES}

If climbing grades are reported, the single standardized metric scale should be used (Table 2). As almost every country has a different grading system to rate the difficulty of a climbing route, the metric scale ${ }^{39}$ should be used for scientific studies. This metric scale is based on
Table 2. Comparison of the recommended climbing grade metric scale for scientific studies to the UIAA, French, and American grades

\begin{tabular}{cccl}
\hline Metric scale & UIAA & French (Fr.) & US-American (YDS) \\
\hline 5.66 & $6-$ & $5 \mathrm{~b} / \mathrm{c}$ & 5.8 \\
6 & 6 & $5 \mathrm{c} / 6 \mathrm{a}$ & 5.9 \\
6.33 & $6+$ & $6 \mathrm{a} / 6 \mathrm{a}+$ & $5.10 \mathrm{a}$ \\
6.66 & $7-$ & $6 \mathrm{a}+/ \mathrm{b}$ & $5.10 \mathrm{~b} / \mathrm{c}$ \\
7 & 7 & $6 \mathrm{~b} / \mathrm{b}+$ & $5.10 \mathrm{~d}$ \\
7.33 & $7+$ & $6 \mathrm{~b}+/ 6 \mathrm{c}$ & $5.11 \mathrm{a} / \mathrm{b}$ \\
7.66 & $8-$ & $6 \mathrm{c}+$ & $5.11 \mathrm{c}$ \\
8 & 8 & $7 \mathrm{a}$ & $5.11 \mathrm{c} / \mathrm{d}$ \\
8.33 & $8+$ & $7 \mathrm{a}+/ 7 \mathrm{~b}$ & $5.12 \mathrm{a} / \mathrm{b}$ \\
8.66 & $9-$ & $7 \mathrm{~b} / 7 \mathrm{~b}+$ & $5.12 \mathrm{~b} / \mathrm{c}$ \\
9 & 9 & $7 \mathrm{c} / 7 \mathrm{c}+$ & $5.12 \mathrm{~d}$ \\
9.33 & $9+$ & $7 \mathrm{c}+/ 8 \mathrm{a}$ & $5.13 \mathrm{a}$ \\
9.66 & $10-$ & $8 \mathrm{a} / 8 \mathrm{a}+$ & $5.13 \mathrm{~b} / \mathrm{c}$ \\
10 & 10 & $8 \mathrm{~b}$ & $5.13 \mathrm{~d}$ \\
10.33 & $10+$ & $8 \mathrm{~b}+/ 8 \mathrm{c}$ & $5.14 \mathrm{a} / \mathrm{b}$ \\
10.66 & $11-$ & $8 \mathrm{c} / 8 \mathrm{c}+$ & $5.14 \mathrm{~b} / \mathrm{c}$ \\
11 & 11 & $9 \mathrm{a}$ & $5.14 \mathrm{~d}$ \\
11.33 & $11+$ & $9 \mathrm{a}+$ & $5.15 \mathrm{a}$ \\
11.66 & $12-$ & $9 \mathrm{~b}$ & $5.15 \mathrm{~b}$ \\
& & &
\end{tabular}

YDS, Yosemite Decimal System

the UIAA scale where whole number UIAA grades are directly converted in metric numbers (eg, UIAA 1 is metric 1.0), and uneven UIAA grades are converted metric numbers ending with 0.33 or 0.66 (Table 2). Thus the lower or future higher grades can similarly be calculated.

It is important to understand that the various international scales are not precisely matched, making comparisons very difficult-eg, converting grade French 8 a to UIAA $9+, 9+/ 10-$ or $10-$. These conversions become even more problematic with the lower grades and other scales, eg, the British grades.

For mountaineering, several systems are currently in use to grade mountain climbs. Alpine mountaineer-

Table 3. Hiking and easy mountaineering grades

1. Easy-Clearly marked low gradient trails.

2. Moderate-Marked steeper trails. Requires some map reading skills.

3. Difficult-Scrambling, paths may be poorly defined. Regular use of hands for difficult sections. Cables may provide additional security on exposed sections. Falls in exposed sections may result in serious injury.

4. Hard-Rope needed to assure some short descents. Short climbing pitches of grade 2-3 (UIAA). Generally good natural belay points are available or pitches are secured by cables. Falls in exposed sections may be fatal or will result in serious injuries.

5. Extreme- Rope required to complete parts of the route or to assure ascent on exposed sections. Equivalent to grade 4.0 UIAA climbing routes. Climbing helmet required due to exposure from rockfall (animals or other walkers). Falls in exposed sections will be fatal. 
ing routes are usually graded based on all of their different aspects, as they can be very diverse. Thus, a mountain route may be graded 5.6 YDS (rock difficulty) (or UIAA metric 4.66), A2 (aid difficulty), WI3 (ice climbing difficulty), M5 (mixed climbing difficulty), $70^{\circ}$ (steepness), $4000 \mathrm{ft}$ (length), VI (commitment level), and many other factors. As there are presently no comparison tables (such as the French mountaineering grading $[\mathrm{F}, \mathrm{PD}, \mathrm{AD}, \mathrm{D}, \mathrm{TD}, \mathrm{ED}$ and $\mathrm{ABO}$ ], the French mountain trekking grades [I, II, III, IV], the New Zealand mountaineering grades [New Zealand Grade 1-7] and many others), we recommend the use the UIAA metric scale (starting with 1.0) when possible. For mountain hiking and easy mountaineering the Hiking grades (Table 3) based on the American Decimal System are proposed. The first 3 grades are basically walking routes. The 2 higher grades are still largely walking routes but will involve some climbing skills and possible rope work.

\section{Conclusion}

We have developed a simple and common protocol to report injuries and illnesses in mountaineering and climbing studies. Comparing the existing scientific studies on mountaineering and climbing has been problematic, ${ }^{19}$ as most studies used different scores and definitions. The proposed retrospective scoring system will facilitate the analysis and surveillance of their frequencies, severity and fatalities, and treatment outcomes. Such analysis can then target interventions to reduce their incidence and improve the safety records of mountaineering and climbing sports, and enable injury comparisons with other sports.

\section{References}

1. Addiss DG, Baker SP. Mountaineering and rock-climbing injuries in US national parks. Ann Emerg Med. 1989;18: 975-979.

2. Bowie WS, Hunt TK, Allen HA Jr. Rock-climbing injuries in Yosemite National Park. West J Med. 1988;149: 172-177.

3. Schussmann LC, Lutz LJ, Shaw RR, Bohn CR. The epidemiology of mountaineering and rock climbing accidents. Wilderness Environ Med. 1990;1:235-248.

4. Paige TE, Fiore DC, Houston JD. Injury in traditional and sport rock climbing. Wilderness Environ Med. 1998;9:2-7.

5. Rooks MD. Rock climbing injuries. Sports Med. 1997;23: 261-270.

6. Rooks MD, Johnston RB 3rd, Ensor CD, McIntosh B, James S. Injury patterns in recreational rock climbers. Am J Sports Med. 1995;23:683-685.
7. Gerdes EM, Hafner JW, Aldag JC. Injury patterns and safety practices of rock climbers. J Trauma. 2006;61: 1517-1525.

8. Josephsen G, Shinneman S, Tamayo-Sarver J, et al. Injuries in bouldering: a prospective study. Wilderness Environ Med. 2007;18:271-280.

9. Jones G, Asghar A, Llewellyn DJ. The epidemiology of rock climbing injuries. Br J Sports Med. 2008;42:773-778.

10. Hearns ST, Fraser MH, Allan DB, McLean AN. Spinal injuries in Scottish mountaineers. Wilderness Environ Med. 2006;17:191-194.

11. Logan AJ, Makwana N, Mason G, Dias J. Acute hand and wrist injuries in experienced rock climbers. $\mathrm{Br} J$ Sports Med. 2004;38:545-548.

12. Rohrbough JT, Mudge MK, Schilling RC. Overuse injuries in the elite rock climber. Med Sci Sports Exerc. 2000;32: 1369-1372.

13. Limb D. Injuries on British climbing walls. $\mathrm{Br} J$ Sports Med. 1995;29:168-170.

14. Schöffl V, Küpper T. Injuries at the 2005 World Championships in Rock Climbing. Wilderness Environ Med. 2006; 17:187-190.

15. Schöffl V, Winkelmann HP. Unfallstatistik an "IndoorKletteranlagen" [Accident statistics at "indoor climbing walls"]. Sportverletz Sportschaden. 1999;13:14-16.

16. Nelson NG, McKenzie LB. Rock climbing injuries treated in emergency departments in the U.S., 1990-2007. Am J Prev Med. 2009;37:195-200.

17. Schöffl V. Fels- und Eisklettern-Eine Risikoanalyse. Hamburg: Diplomica Verlag; 2009:Vol 1, p 100.

18. Schöffl V, Morrison AB, Schwarz U, Schöffl I, Küpper T. Evaluation of injury and fatality risk in rock and ice climbing. Sport Med. 2010;40:657-679.

19. Schöffl V, Schöffl I, Schwarz U, Hennig F, Küpper T. Injury-risk evaluation in water ice climbing. Med Sport. 2009;2:32-38.

20. Schwarz U, Küpper T, Schöffl I, Dickschas J, Schöffl V. Eisklettern-Unfälle und Überlastungen. Sport Ortho Sport Trauma. 2008;24:235-238.

21. American-Alpine-Club. Accidents in North American mountaineering. Am Alpine Club. 2006;9:59.

22. Canadian-Alpine-Club. Accidents in North American Mountaineering. Canmore, AB, Canada: Canadian Alpine Club; 2005:Vol 1.

23. DAV Bergunfallstatistik 2006-2007. München; 2008.

24. Schindera ST, Triller J, Steinbach LS, et al. Spectrum of injuries from glacial sports. Wilderness Environ Med. 2005;16:33-37.

25. McIntosh SE, Campbell AD, Dow J, Grissom CK. Mountaineering fatalities on Denali. High Alt Med Biol. 2008;9: 89-95.

26. McIntosh SE, Leemon D, Visitacion J, Schimelpfenig T, Fosnocht D. Medical incidents and evacuations on wilderness expeditions. Wilderness Environ Med. 2007;18: 298-304.

27. Shlim DR, Houston R. Helicopter rescues and deaths among trekkers in Nepal. JAMA. 1989;261:1017-1019. 
28. Malcom M. Mountaineering fatalities in Mt Cook National Park. N Z Med J. 2001;114:78-80.

29. Salisbury R. The Himalayan Database: The Expedition Archives of Elizabeth Hawley. Golden, CO: American Alpine Club; 2004.

30. Monasterio ME. Accident and fatality characteristics in a population of mountain climbers in New Zealand. $N$ Z Med J. 2005;118:U1249.

31. Fuller CW, Ekstrand J, Junge A, et al. Consensus statement of injury definitions and data collection procedures in studies of football (soccer) injuries. Scand J Med Sci Sports. 2006;16:83-92.

32. Fink A, Kosecoff J, Chassin M, Brook RH. Consensus methods: characteristics and guidelines for use. Am J Public Health. 1984;74:979-983.

33. Windsor JS, Firth PG, Grocott MP, Rodway GW, Montgomery HE. Mountain mortality: a review of deaths that occur during recreational activities in the mountains. Postgrad Med J. 2009;85:316-321.
34. Veldman A, Fischer D, Brand J, et al. Proposal for a new scoring system in international interhospital air transport. $J$ Travel Med. 2001;8:154-157.

35. Rae K, Britt H, Orchard J, Finch C. Classifying sports medicine diagnoses: a comparison of the International classification of diseases 10-Australian modification (ICD-10$\mathrm{AM}$ ) and the Orchard sports injury classification system (OSICS-8). Br J Sports Med. 2005;39:907-911.

36. Rae K, Orchard J. The Orchard Sports Injury Classification System (OSICS) version 10. Clin J Sport Med. 2007;17(3): 201-204.

37. Orchard J. Orchard Sports Injury Classification System (OSICS). Sport Health. 1995;11:39-41.

38. Firth PG, Zheng H, Windsor JS, et al. Mortality on Mount Everest, 1921-2006: descriptive study. BMJ. 2008;337: a2654.

39. Schöffl V, Hochholzer T, Winkelmann H P, Strecker W. Pulley injuries in rock climbers. Wilderness Environ Med. 2003;14:94-100. 